\title{
Thyrotoxic Periodic Paralysis - A Case Report of a Rare Cause of Paralysis in a 39-Year-Old Asian Man
}

\author{
R. Benson Jones Jr, MD, and James Uricheck, MD
}

\section{INTRODUCTION}

Uncontrolled hyperthyroidism has a myriad of presentations. Classically, symptoms include weight loss, tremor, palpitations, shortness of breath, diarrhea, anxiety, and heat intolerance. A rare manifestation of hyperthyroidism is thyrotoxic periodic paralysis (TPP). Periodic paralysis is a musculoskeletal channelopathy manifested by episodes of painless muscle weakness often precipitated by heavy exercise, fasting, or high carbohydrate meals. Although classically associated with painless weakness; cramping, myalgias, and stiffness can also occur prior to the episodes as prodromal symptoms. Neurologic examination during an attack typically demonstrates proximal more than distal muscle weakness, and the upper extremities are more commonly affected than the lower extremities. ${ }^{1-4}$ Consciousness and sensation are preserved, and respiratory muscle involvement is exceedingly rare. Episodes of weakness can last from a few hours up to 72 hours with intermittent recovery between attacks. Patients most often have diminished deep tendon reflexes, but reflexes may be preserved in some cases. We present a case of TPP, discuss the differential diagnosis of periodic paralysis, and review the pathophysiology and management of TPP.

\section{CASE DESCRIPTION}

A 39-year-old man with a past medical history of hyperthyroidism presented with 5 days of progressive, bilateral leg weakness and neck pain. On the day of presentation, the patient was unable to walk normally. He reported a 40-pound weight loss over the 3 months prior to admission. He had been diagnosed with a "thyroid problem" five years ago in Taiwan after having a similar episode, but he had stopped taking the prescribed medication when he arrived in the United States two years ago. He never received radioactive iodine. He endorsed palpitations, dizziness, headache, and diaphoresis. He denied chest pain, shortness of breath, nausea, vomiting, and diarrhea. On exam, he was diaphoretic, but awake, alert and oriented without distress. His pupils were equal, round, and reactive without lid lag or proptosis, although, on repeat examination there was concern for lid retraction in the left eye. There was mild thyromegaly and he was tachycardic with a grade $2 / 6$ holosystolic murmur loudest in the left sternal border. He had no sensory deficits, but
2/5 strength in hip and knee flexion and extension bilaterally, and $3 / 5$ strength in plantar flexion and extension bilaterally. ECG showed sinus tachycardia at a rate of 106 beats per minute with bigeminy and nonspecific $T$ wave changes. Labs notable for a potassium of $1.7 \mathrm{mmol} / \mathrm{L}$ (reference range $3.4-4.5 \mathrm{mmol} / \mathrm{L}$ ), magnesium of $1.3 \mathrm{mEq} / \mathrm{L}$ (reference range $1.3-2.1$ $\mathrm{mEq} / \mathrm{L}$ ), thyrotropin $<0.02 \mathrm{mIU} / \mathrm{L}$ (reference range 2.5-4.5 $\mathrm{mIU} / \mathrm{L}$ ), free $\mathrm{T} 4>7.8 \mathrm{ng} / \mathrm{dL}$ (reference range $0.7-1.7 \mathrm{ng} /$ $\mathrm{dL}$ ), and free $\mathrm{T} 3$ of $23.3 \mathrm{pg} / \mathrm{mL}$ (reference range 2.0 - 4.4 $\mathrm{pg} / \mathrm{mL}$ ). CT scan of the orbits without the administration of intravenous contrast showed no extraocular muscle involvement or proptosis. Ultrasound of the thyroid showed heterogenous texture and innumerable nodules in both lobes suggestive of thyroiditis.

Endocrinology was consulted for hyperthyroidism, and recommended methimazole $30 \mathrm{mg}$ daily in addition to potassium replacement and propranolol $40 \mathrm{mg}$. Ophthalmology was consulted and there was no evidence of thyroid optic neuropathy, but they did comment on possible lid retraction in the left eye and enophthalmos in the right eye. The patient was admitted to the ICU for frequent laboratory checks and close monitoring. About 6 hours following potassium replacement, antithyroid therapy and beta blockade, the patient's strength and potassium improved.

\section{DIFFERENTIAL DIAGNOSIS}

Causes of potassium loss can be classified as renal or nonrenal, or separately by transcellular shift, one of the causes of which is periodic paralysis. Causes of periodic paralysis include hyperkalemia, hypokalemia, familial hypokalemic periodic paralysis, or Andersen syndrome, an autosomal dominant inherited defect of the inward rectifying potassium channel associated with short stature, hypertelorism, clinodactyly, and micrognathia. ${ }^{5}$

\section{OUTCOME AND FOLLOW UP}

Following potassium replacement, the patient was discharged on methimazole $30 \mathrm{mg}$ daily without any neurologic symptoms. Despite having been scheduled for an appointment with Endocrinology, the patient was lost to follow-up. 


\section{DISCUSSION}

TPP is a rare, potentially life-threatening complication of hyperthyroidism. TPP occurs in about two percent of Asian patients with hyperthyroidism compared to 0.1 to 0.2 percent of the general population. ${ }^{3}$ Despite the fact that hyperthyroidism occurs more frequently in women, over $95 \%$ of TPP cases occur in men. ${ }^{6}$ Disease onset typically occurs between ages 20 and 50 years, whereas familial hypokalemic periodic paralysis and Andersen syndrome occur in patients typically under the age of 20 years.7-8 The pathophysiology of TPP relates to hypokalemia: thyroid hormone increases sodiumpotassium ATPase activity on skeletal muscle, forcing potassium to the intracellular space. The resultant hyperpolarized muscle membrane reduces the excitability of the muscle tissue. Excess thyroid hormone also increases insulin resistance and beta-adrenergic responsiveness. Insulin and epinephrine both enhance sodium-potassium ATPase activity, further forcing potassium into the cell.7-8

The management of TPP consists of potassium repletion and normalization of thyroid hormone. Patients are typically hospitalized and monitored on telemetry due to the risk of cardiac arrhythmias in the setting of labile potassium levels. Correction of potassium provides the mainstay of treatment, and it is important to check potassium levels frequently due to the risk of rebound hyperkalemia. ${ }^{9}$ Intravenous potassium provides more rapid normalization of potassium levels and is the recommended treatment modality. ${ }^{10}$ As always with hypokalemic patients, concurrent repletion of hypomagnesemia, if present, is recommended as well. For patients who are found to be refractory to potassium repletion monotherapy or who are deemed to be at high risk of complications due to arrhythmia, concurrent therapy with propranolol, methimazole, or both may be utilized as well. Preventative therapy requires proper monitoring of TSH with the goal of sustaining a euthyroid state with methimazole. Empiric potassium repletion has not been shown to be an effective deterrent?

\section{KEY POINTS}

Thyrotoxic periodic paralysis is a rare complication of hyperthyroidism consisting of painless muscle weakness and hypokalemia. Acute management involves potassium replacement and propranolol, while long term prevention requires methimazole to maintain euthyroid status.

\section{REFERENCES}

1. Ober KP. Thyrotoxic periodic paralysis in the United States. Report of 7 cases and review of the literature. Medicine (Baltimore). 1992;71(3):109-20.

2. Kelley DE, Gharib H, Kennedy FP, Duda RJ, Mcmanis PG. Thyrotoxic periodic paralysis. Report of 10 cases and review of electromyographic findings. Arch Intern Med. 1989;149(11):2597-600.

3. Hsieh MJ, Lyu RK, Chang WN, et al. Hypokalemic thyrotoxic periodic paralysis: clinical characteristics and predictors of recurrent paralytic attacks Eur J Neurol. 2008;15(6):559-64.

4. Hsieh, Susan. "A Unique Presentation of Thyrotoxic Hyookalemic Periodic Paralysis." Proceedings of UCLA Healthcare, 2014, proceedings.med.ucla. edu/wp-content/uploads/2016/11/A-Unique-Presentation-of-ThyrotoxicHypokalemic-Periodic-Paralysis_CB_Edited.pdf.

5. Sansone V, Griggs RC, Meola G, et al. Andersen's syndrome: a distinct periodic paralysis. Ann Neurol. 1997:42(3):305-12.

6. Rhee EP, Scott JA, Dighe AS. Case records of the Massachusetts General Hospital. Case 4-2012. A 37-year-old man with muscle pain, weakness, and weight loss. N Engl J Med. 2012;366(6):553-60.

7. Annie W. C. Kung; Thyrotoxic Periodic Paralysis: A Diagnostic Challenge, The Journal of Clinical Endocrinology \& Metabolism, Volume 91, Issue 7, 1 July 2006, Pages 2490-2495.

8. Lin SH. Thyrotoxic periodic paralysis. Mayo Clin Proc. 2005:80(1):99-105

9. Manoukian MA, Foote JA, Crapo LM. Clinical and metabolic features of thyrotoxic periodic paralysis in 24 episodes. Arch Intern Med. 1999;159(6):601-6.

10. Cesur M, Bayram F, Temel MA, et al. Thyrotoxic hypokalaemic periodic paralysis in a Turkish population: three new case reports and analysis of the case series. Clin Endocrinol (Oxf). 2008;68(1):143-52 